ISSN 1518-3483

Licenciado sob uma Licença Creative Commons

\title{
Alegação para uma epistemologia de segunda ordem na formação de professores
}

\author{
Allegation for na epistemology of second order \\ in teachers' training
}

Orlando Fernández Aquino, Alberto Matías González*

Universidade de Uberaba (UNIUBE), Uberaba, MG, Brasil

\section{Resumo}

No presente ensaio apresenta-se uma discussão sobre alguns dos problemas e fragilidades que, a juízo dos autores, apresenta hoje a área de formação de professores. O texto foi elaborado a partir de uma pesquisa de terceiro grau; ou seja, por meio da revisão de estudos nacionais e internacionais que por sua vez tinham mapeado a situação da área. Ao mesmo tempo, o estado atual da área de formação docente julga-se desde uma epistemologia de segunda ordem, para tratar de visualizar quais seriam as limitações dos enfoques filosóficos da ciência moderna que permeiam esse campo, e como supera-los pela via do salto epistemológico. Chega-se à conclusão que uma das maneiras possíveis de superação das fragilidades identificadas seria avançar para um enfoque pluridisciplinar e interdisciplinar de tratamento dos objetos da pesquisa em formação de professores, junto a fundamentações teóricas de

* OFA: Doutor em Ciências Pedagógicas, e-mail: ofaquino@gmail.com

AMG: Doutor em Gestão Ambiental e Desenvolvimento Sustentável, e-mail: albertomg1122@gmail.com 
maior relevância e o passo a pesquisas teóricas e empíricas de maior consistência metodológica, o que permitiria a consolidação da área enquanto disciplina científica.

Palavras-chave: Formação de professores. Problemas e fragilidades da formação docente. Epistemologia de segunda ordem.

\begin{abstract}
In the present essay, one shows a discussion about some of the problems and fragilities that, according to the authors, shows nowadays an area of teachers' training. The text was made from a third grain research; that is, through a review of national and international studies which, for their time, had mapped the situation of the area. At the same time, the present state of the area of teaching training is judged since an epistemology of second order, for treating of visualizing what would be the limitations of philosophical focuses of the modern science, which permeates that field, and how to overcome them by epistemological jump via. One arrives to conclusion that one of the possible ways of overcoming fragilities identified would be advance to a pluridisciplinary and interdisciplinary focus of treating objects of research in teachers' training, together with theoretical foundations of greater relevance and the step to theoretical and empirical researches of greater methodological consistence, which would allow consolidation of area while scientific discipline.
\end{abstract}

Keywords: Teachers' training. Problems and fragilities of teaching training. Second order epistemology. 


\section{Introdução ${ }^{1}$}

\section{O problema}

A formação de professores não é uma ciência. É uma área emergente de atuação profissional e de pesquisa que vem se configurando rapidamente desde finais da década de 1980, como diferentes autores têm explicado (MARCELO, 1999; GATTI, 2001; ANDRÉ, 2010; ROMANOWSKI, 2012) ${ }^{2}$. Segundo dados fornecidos por esta última investigadora, entre 1987 e 2011 foram defendidas, nos Programas de Pós-graduação em Educação de Brasil, mais de 5 mil teses e dissertações nesta área.

Por sua vez, André (2010), com base em estudos precedentes (OLIVEIRA, 2000; SOARES, 2000) explica que na virada entre a década 1990 e a de 2000 o campo da Didática começou a ser invadido por diversos estudos sobre formação de professores. Ao mesmo tempo, nesse momento identificou-se também que a formação de professores se constitui numa disciplina específica, que começava a ser independente de áreas tradicionais como a Didática, a Prática de Ensino e Currículo. Sendo assim, o caráter recente da área - e a consequente falta de perspectiva histórica - constitui um obstáculo do qual devemos estar conscientes para uma análise profunda de suas necessidades e obstáculos.

Na nossa modesta opinião, a formação de professores - nascida no campo disciplinar da Didática - continua, até hoje, atrelada ao cordão umbilical desta ciência, da qual ainda necessita tomar emprestados

1 Com ajustes, o presente texto foi apresentado na mesa redonda "Produção científica sobre formação docente: fragilidades e potencialidades" no VIII Encontro de Pesquisa em Educação e III Congresso Internacional Trabalho Docente e Processos Educativos. Universidade de Uberaba, MG, 22 a 24 de Setembro de 2015.

2 Isso não significa que, anterior a esse período, não existissem pesquisas esparsas sobre formação de professores. No Brasil, como bem mostram os estudos existentes (GOUVEIA, 1971, 1976; GATTI, 2001), desde a década de 1930, em que foi criado o Instituto Nacional de Estudos e Pesquisas Educacionais, no conjunto da pesquisa educacional, já existia uma preocupação pelos estudos entorno do professor. Não deve se confundir a conformação da área com as pesquisas esparsas sobre o tema. 
referenciais teóricos, métodos de investigação e procedimentos de análise de dados. Isso explica, em muitas ocasiões, a confusão entre a Didática e a formação de professores, nomeadamente no tocante a seu objeto de estudo. A emergência de uma nova área no seio da Didática deve ser entendida como uma necessidade histórica e contextual do desenvolvimento da Pedagogia em nível internacional, fato ocorrido no final dos anos 1980 e no começo dos 90 .

Felizmente, tanto em nosso país como em nível internacional, contamos com um renomado número de investigadores, de Grupos de Pesquisa e de jornais científicos que têm produzido valioso material teórico e empírico sobre os avanços, problemas e fragilidades da emergente disciplina. Com base em alguns desses autores, como: Zeichner (2009); Marcelo (1997, 1998); André (1999, 2002, 2010); Romanowski (2012, 2014); Libâneo (2011); Aquino e Borges (2014); Gatti (2009); Gatti et al. (2011); Soares (2000) e Brzinski (2006), Nicolescu (2006) e Sotolongo e Delgado (2007), fazemos uma abstração geral das fragilidades da área e, ainda, considerando as devidas exceções, podemos dizer que essas fragilidades se localizam em cinco aspectos de grande transcendência para a área em estudo: a) não todas as pesquisas se apoiam em referenciais teóricos relevantes; b) falta de consenso sobre o objeto de estudo da área; c) dificuldades no uso dos métodos de coleta de dados e dos métodos de análise dos resultados, assim como sua relação com o contexto no qual se realiza a investigação; d) a formação dos profissionais da área - professores e pesquisadores apresenta ainda muitas fragilidades; e) o movimento científico da área está pautado ainda pelo paradigma clássico da modernidade, com escassas aberturas para uma epistemologia de segunda ordem ${ }^{3}$.

3 Chamamos de epistemologia de segunda ordem o enfoque complexo e contextual que supera as dualidades e reducionismos da ciência moderna, como a oposição sujeito-objeto, acima-abaixo, subjetivo-objetivo. A epistemologia de segunda ordem converge com a concepção dialético materialista do mundo sobre o automovimento dialético da matéria. Postula, entre outras questões, a necessidade de contextualizar e mediar os processos cognitivos e de apropriação da realidade por meio da praxe social quotidiana em que se realiza a investigação e está imerso o sujeito cognitivo (SOTOLONGO; DELGADO, 2006). 
Nos apontamentos que seguem discutimos cada um desses problemas, com a exceção do $5^{\circ}$ aspecto, o qual integramos na discussão dos demais itens. Na leitura de nossas reflexões deve ficar claro que: a) não se trata da negação dos resultados nem do avanço de uma área ainda em formação, nem muito menos de negar o esforço profissional e sério de seus melhores expoentes; b) o tratamento de cada problema numa reflexão independente obedece a uma necessidade expositiva e precisa ser entendido como uma interpretação, intimamente ligada a totalidade do campo; c) os problemas aqui abordados são recorrentes e, dada a brevidade das reflexões, nem todos os autores serão citados ou resenhados; d) cada ponderação deve ser compreendida apenas como o que é: uma reflexão ensaística para a discussão do tema.

\section{O objeto de estudo}

Um dos problemas que a área de formação de professores precisa resolver refere-se a falta de consenso existente em relação a seu objeto de estudo, propriamente dito, e a maneira como o objeto é abordado nas pesquisas. Mesmo assim, deve-se reconhecer que investigadores, de âmbito internacional e nacional, têm dedicado profundas reflexões a esse problema, sem que se visualize ainda uma aproximação de critérios a esse respeito; ou seja, um consenso que permita avançar sem que necessariamente os discernimentos sejam unânimes.

Marcelo García (2009), por exemplo, oferece a nosso ver, uma das conceptualizações mais completas sobre a formação de professores.

A Formação de Professores é a área de conhecimentos, investigação e de propostas teóricas e práticas que, no âmbito da Didática e da Organização Escolar, estuda os processos através dos quais os professores - em formação ou em exercício - se implicam individualmente ou em equipa, em experiências de aprendizagens através das quais adquirem ou melhoram os seus conhecimentos, competências e disposições, e que lhes permite intervir profissionalmente no desenvolvimento de 
seu ensino, do currículo e da escola, com o objetivo de melhorar a qualidade da educação que os alunos recebem (MARCELO, 2009, p. 26).

Percebemos que a conceptualização desta área, destacada pelo teórico e pesquisador Marcelo Garcia, como um espaço amplo de conhecimentos, de investigação e de propostas teóricas sobre a formação e experiências professionais dos professores, abre sim dúvidas, um caminho interessante para avançar neste aspecto.

Uma visão mais abrangente sobre esse conceito aparece em Imbernón (2002), que "concebe a formação docente como um processo contínuo de desenvolvimento profissional, que tem início na experiência escolar e prossegue ao longo da vida [...] e abrange questões relativas a salário, carreira, clima de trabalho, estruturas, níveis de participação e de decisão" (IMBERNÒN, 2002, apud ANDRÉ, 2010, p. 175).

Nos últimos anos, a categoria desenvolvimento profissional docente ganha espaço na literatura da área. Dentre outros autores, Marcelo (2009) substituiu os conceitos de formação inicial e continuada pelo conceito de desenvolvimento profissional e centralizaram suas discussões no mesmo. (ANDRÉ, 2010). Marcelo García (2009) destaca ainda que o desenvolvimento profissional deve atender também às representações, aos conceitos e às crenças dos professores, pois essas concepções afetam as aprendizagens sobre o aprender a ensinar e em algumas situações dificultam as mudanças de comportamento. Assim sendo, "torna-se, pois, necessário, fazer vir à tona essas representações e analisá-las criticamente, junto aos professores, para poder encontrar formas de transformá-las na direção desejada" (MARCELO, 2009, apud ANDRÉ, 2010, p. 176).

De outro lado, tanto Bolívar (2006) quanto Marcelo (2009), destacam também a centralidade do conceito de identidade profissional como sendo objeto da formação de professores. Na visão deles, a identidade profissional é uma dimensão inseparável do desenvolvimento profissional, pois aspectos tais como a escola, as reformas educativas, os contextos políticos, a disponibilidade dos professores para aprender a profissão, os conhecimentos sobre as matérias que ensinam e suas metodologias, as 
experiências passadas e a vulnerabilidade dos professores, são também objeto de preocupação e estudo dos investigadores da área.

De acordo com o nosso ponto de vista, não é possível abrir mão de conceitos fundantes como formação inicial, formação continuada, formação em serviço, supervisão clínica, trabalho metodológico ou trabalho didático, trabalho docente e outros que advém da melhor tradição, para serem substituídos pelo conceito de profissionalização docente. Este último tem se mostrado amplo e flexível e seu uso se justifica plenamente, é demasiado abrangente e conduz, inequivocamente, à diluição do objeto de estudo da área. Com esses e outros conceitos amplamente usados na formação de professores, é preciso equacionar o mapa epistemológico da área, destacando os nexos conceituais, sem abrir brechas para a fragmentação do objeto de estudo. O que se precisa hoje, justamente, é ganhar clareza teórica sobre a delimitação e o objeto do campo.

Como mostram vários dos estudos citados neste trabalho (MARCELO, 1998; ZEICHNER, 2009; ANDRÉ, 2010), desde a década de 1990 até hoje, as pesquisas sobre formação de professores apresentam uma oscilação no tratamento de objetos como a formação inicial, a formação continuada, os processos de profissionalização docente, os estudos centrados na figura do professor, suas representações, crenças, etc. Esses objetos são quase sempre abordados numa perspectiva disciplinar e de forma descontextualizada, à maneira do paradigma clássico da modernidade. Em nosso enfoque, esse caminho metodológico tem conduzido a fragmentação da qual se acusa hoje a formação de professores. Para a superação desses entraves, o salto paradigmático da pesquisa na área de formação de professores se configura como uma necessidade da ciência contemporânea.

A luz dessa perspectiva, a formação de professores precisa de uma unidade de análise que contenha os nexos e as relações essenciais correspondentes à totalidade de seu campo. Essa unidade de análise poderia ser o processo de formação, de profissionalização e de compreensão da identidade profissional dos docentes, seja na formação inicial ou na continuada, ou qualquer modalidade, programa ou modelo de formação. 
Esse objeto-unidade de análise que acabamos de mencionar precisa ser examinado nas suas mediações contextuais com as situações acadêmicas, institucionais, políticas e trabalhistas nas que se realiza a formação. A formação dos professores, como todo processo socioeducativo é sempre situada social e historicamente.

Esse objeto da formação dos professores precisa ser entendido, também, como uma unidade complexa, composta por diferentes níveis de realidade ${ }^{4}$ que se interpenetram e se auto-organizam mutuamente. Por exemplo, em toda e qualquer turma de formação de professores, como em qualquer sala de aula, temos uma realidade local, pontual, visível, integrada pelos sujeitos que a conformam e com a qual mediamos os formadores no dia a dia. Os professores formadores e investigadores fazem parte orgânica dessa realidade. Por baixo desse fato local e pontual, existem diversos níveis de realidades formadas por subjetividades, intersubjetividades, histórias de vidas, anseios, ciúmes, aspirações e problemas econômicos que afetam também os processos de formação dos profissionais. Acima desse nível local de realidade, existem outros níveis fatuais que estendem seus tentáculos para os níveis mais profundos, enquanto que as realidades profundas se enlaçam com a cúspide. Nesse nível superior situam-se as políticas, os centros formadores, os programas de formação, o desenvolvimento da ciência e da tecnologia, as condições de emprego, salário e carreira, dentre outros. Em outras palavras, cada objeto particular de estudo na formação de professores, como na educação em geral, é um

4 Os níveis de realidade são um descobrimento da física quântica, em meados do século XX. São definidos da seguinte maneira: "Há que compreender por nível de Realidade um conjunto de sistemas invariantes a ação de um número de leis gerais: por exemplo, as entidades quânticas submetidas as leis quânticas, as quais entram em ruptura radical com as leis do mundo da microfísica. Ou seja, que dois níveis de Realidade são diferentes se, passando de um a outro, há ruptura das leis e ruptura dos conceitos fundamentais". O autor explica ainda que Husserl e outros investigadores descobriram "a existência de diferentes níveis de percepção da realidade por parte do sujeito-observador". Agrega que eles foram "pioneiros na exploração de uma realidade multidimensional e multirreferencial na qual o ser humano pode reencontrar o seu lugar e sua verticalidade" (NICOLESCU, 2006, p. 17-18). 
processo objetivo, constituído por diferentes níveis de realidade, às vezes circulares, às vezes reticulares, sempre hologramáticas.

Como dito antes, a formação de professores se constitui como área emergente no seio de outras disciplinas educacionais, configurando uma nova concepção de ciência e de pesquisa. Desde meados do século $\mathrm{XX}$, os nexos entre as diferentes disciplinas que constituem um campo teórico colocam-se como uma necessidade do progresso do conhecimento científico, dando passo à pluridisciplinaridade e à interdisciplinaridade (NICOLESCU, 2006). A formação de professores não constitui, obviamente, uma exceção no contexto da ciência contemporânea. É um campo complexo de formação profissional, pesquisa, profissionalização, identidade, cultura profissional, conhecimentos e práticas identitárias, cuja constituição intervém disciplinas diversas como a Didática, a Pedagogia, a Epistemologia das ciências particulares, a Psicologia geral e educacional, a História e a Filosofia da educação, a Sociologia do trabalho, os estudos de gênero, raça e alteridades, a Antropologia cultural e outras que atravessam o campo. Sendo assim, o objeto de investigação na formação de professores, qual seja, precisa ser pensado também de maneira multidisciplinar e interdisciplinar. Como bem explicado a seguir:

A pluridisciplinaridade concerne o estudo de um objeto de uma sola e mesma disciplina por várias disciplinas a sua vez. Por exemplo, um quadro de Giotto pode ser estudado pela observação da história da arte cruzada com a de a física, a química, a história das religiões, a história de Europa e a geometria [...] O conhecimento do objeto na sua própria disciplina se aprofunda com uma contribuição pluridisciplinar fecunda. Dito de outra maneira, o avanço pluridisciplinar desborda as disciplinas, mas sua finalidade permanece inscrita no marco da investigação disciplinária (NICOLESCU, 2006 p. 34-35).

Nicolescu (2006), também nos leva à compreensão da necessidade dos estudos não apenas pluridisciplinares na formação de professores, como também da urgente captação do caráter interdisciplinar que devem assumir as pesquisas da área em questão: 
A interdisciplinaridade tem uma ambição diferente da pluridisciplinaridade. Concerne a transferência de métodos de uma disciplina para outra. Podem distinguir-se três grãos de interdisciplinaridade: a) um grão de aplicação. Por exemplo, os métodos da física nuclear transferidos para a medicina conduzem a aparição de novos tratamentos do câncer; b) um grão epistemológico: por exemplo, a transferência dos métodos da lógica formal no campo do direito gera análises interessantes na epistemologia do direito; c) um grão de engendramento de novas disciplinas. Por exemplo, a transferência de métodos do campo das matemáticas ao campo da física tem gerado a física matemática [...] da informática a arte, a arte informática. Como a pluridisciplinaridade, a interdisciplinaridade desborda as disciplinas, mas sua finalidade permanece também inscrita na investigação disciplinaria. Devido a esse seu terceiro grão, a interdisciplinaridade contribui ao big bang disciplinário (NICOLAESCU, 2006, p. 35, grifo do autor).

Temos citado em extenso os trechos anteriores para pensarmos com Nicolescu (2006) a urgência epistemológica que hoje desafia a formação de professores. Quando observamos as fragilidades de nossa área e a colocamos no contexto dos avanços paradigmáticos da ciência complexa ou epistemologia de segunda ordem, percebemos que a disciplina está sendo vítima do big bang interdisciplinar. A partir dos conhecimentos filosóficos que hoje temos ao nosso alcance, parece que há um caminho viável para fortalecer o campo disciplinar da formação de professores, que é a abordagem de nossos objetos de investigação desde os enfoques da pluridisciplinaridade e da interdisciplinaridade. Como explicado acima, os enfoques pluridisciplinar e interdisciplinar não dinamitam o campo disciplinar, antes bem o aprofundam e consolidam. Justamente, o que estamos alegando é a necessidade de consolidação disciplinar da formação de professores pela via do salto epistemológico no tratamento de nossos objetos de pesquisa.

\section{A questão teórica}

Um investigador de grande reconhecimento internacional Zeichner (2009) - faz um exame dos textos que integraram o painel da 
American Educational Research Association (AERA), sobre temas específicos da formação inicial de professores nos Estados Unidos. A primeira preocupação levantada pelo pesquisador na sua importante agenda sobre a pesquisa na formação de professores refere-se, justamente, ao problema da fragilidade terminológica que se observa na área. Estas são as suas palavras:

Há muita inconsistência e confusão no que diz respeito à definição dos termos atualmente usados em pesquisas, tais como certificação "alternativa" e "tradicional", "escola de desenvolvimento profissional", "portfolio" e "pesquisa-ação" [...] Alguns estudos tentam estabelecer comparações entre categorias [...] sem definir claramente o que está sendo comparado. Todos os aspectos da formação docente, inclusive as abordagens de ensino, currículo e arranjos organizacionais, deveriam ser definidos claramente, consistentemente, e com suficiente especificidade para permitir a acumulação de conhecimento por meio de investigações sobre a natureza e o impacto de diferentes aspectos da formação docente. Por exemplo, pesquisas sobre o impacto de determinadas estratégias de formação, tais como estudos de caso e pesquisa-ação, precisam discutir as maneiras nas quais essas estratégias são conceitualizadas e introduzidas para os professores em formação e como seu uso é facilitado e encorajado (ZEICHNER, 2009, p. 17).

No Brasil, em um estudo publicado por André (2009), a autora expõe uma síntese da produção acadêmica dos pós-graduandos em educação no período de 1999-2003. Ao mesmo tempo, os resultados de tal investigação são comparados com outro estudo similar, referente ao período de 1990-1998. A investigadora se depara com aquilo que a maioria dos futuros pesquisadores não faz a referência aos autores ou a perspectiva teórica que lhe serve de embasamento para a realização da investigação. Nesse cruzamento de dados, apenas $26 \%$ dos investigadores faz alguma referência ao autor ou a teoria na qual se apoia. Tomando no seu conjunto os poucos trabalhos em que se declaram as fontes teóricas, o panorama se apresenta também como uma dispersão dos referenciais que alimentam a pesquisa na área. Há autores, por exemplo, que apenas se referenciam em uma pesquisa. Como dado curioso está o fato de que de um total de 1.183 trabalhos 
revisados, o autor mais citado é Vigotski, o qual aparece em apenas 43 citações. Ao mesmo tempo, a autora menos citada é Bardam, com 13 citações.

Como se compreenderá, a formação de professores como área emergente não se consolidará até que seus fundamentos epistemológicos não sejam esclarecidos. Não queremos expressar questões ociosas, que todos sabemos, mas sem a formalização das teorias que sustentam a ciência não é possível produzir conhecimentos novos em nenhuma área. Todas as ciências consolidadas têm claros seus referencias teóricos, mesmo que em constante mutação e reacomodo, em cada etapa de seu desenvolvimento histórico e contextual.

\section{O problema do método}

Conexo com as problemáticas da teoria e do objeto de investigação, temos outro dilema na formação de professores que precisa ser assumido pelos investigadores. Falemos então dos problemas de método. Marcelo García (1997) realiza um balanço interessante das pesquisas realizadas na Europa, Austrália, América do Norte e Japão sobre a formação de professores nessa década. Os temas mais cultivados são: o aprender a ensinar, a formação inicial, a formação continuada, as representações e crenças dos professores, os estágios supervisionados, o professor reflexivo e o conhecimento didático do conteúdo. De modo geral, os métodos mais comuns usados são os depoimentos, as entrevistas, os surveys e o questionário. As fragilidades metodológicas dessas pesquisas vão sendo apontadas aqui e ali pelo autor. Para não nos estender demasiado, mencionamos apenas algumas críticas metodológicas sobre as pesquisas relacionadas aos conhecimentos dos professores. Marcelo afirma que essas investigações apresentam limitações "devido às amostras tão reduzidas, à diversidade de contextos e à heterogeneidade na metodologia da pesquisa sobre aprender a ensinar" (KAGAN, 1992, apud MARCELO, 1997, p. 53). Ao mesmo tempo, traz à tona as palavras de Carter (1990): 
Insistindo sobre isso, Carter declara que "os resultados apresentam-se de forma variada: disposições, orientações, perspectivas, conhecimentos, preocupações ou compromissos e, apesar da aparente diferença em seu significado, esses termos frequentemente são empregados de forma indistinta. Muitas vezes os contextos se definem de forma insatisfatória e variam muito de um estudo para outro" (CARTER, 1990, apud MARCELO, 1997, p. 54). Essas limitações persistem nas pesquisas que estão sendo realizadas atualmente, de maneira que o objetivo de ir construindo um modelo de desenvolvimento e aprendizagem profissional vê-se limitado pelas dificuldades de comparação entre as diversas pesquisas realizadas (MARCELO, 1997, p. 53-54, grifo nosso).

Por sua vez, nos Estados Unidos, Zeichner (2009) considera que:

Um segundo aspecto dos modelos de pesquisa sobre formação docente que precisa ser enfatizado é a completa descrição dos métodos de coleta de dados e análise e dos contextos nos quais a pesquisa foi realizada. Muitos estudos examinados neste relatório fornecem informações inadequadas sobre como os dados foram coletados e analisados. Isso torna difícil, senão impossível, avaliar a credibilidade das conclusões obtidas pelos pesquisadores. Do mesmo modo, muitos estudos conduzidos dentro dos limites de disciplinas individuais não situaram tais disciplinas dentro dos cursos, instituições e não especificaram os contextos políticos nos quais eles existiam. Inúmeras pesquisas que discutiram a permanência dos professores no magistério [...] não forneceram nenhuma descrição das características das escolas e das comunidades nas quais os professores lecionavam (ZEICHNER, 2009, p. 17, grifo nosso).

No caso brasileiro, na investigação realizada por André (2009) sobre as teses e dissertações defendidas na área durante as décadas de 1990 e 2000, a autora relata que os procedimentos de pesquisa mais usados foram o microestudo e a análise de depoimentos. Com menos ocorrências foram usados a entrevista, o questionário, a análise de documentos e a observação. Destacamos que nesse período existiam muitas pesquisas pontuais, que abrangiam situações muito específicas, com procedimentos 
pobres de coleta e análise de dados. Nessa mesma investigação, a pesquisadora descobre que os autores dos relatórios se limitavam a reproduzir o que diziam os professores, mas que há escassos esforços por entender os contextos de produção de tais discursos. Ou seja, que a pesquisa não aprofunda nas razões que levam os professores a sustentar suas opiniões, ou a quem se dirigem esses discursos e que pretendem. Também, nessas pesquisas não é possível identificar o esforço de ir além da constatação na procura de caminhos para o aperfeiçoamento da prática profissional, ou para a colaboração entre pesquisadores e professores. A autora afirma que por essa via corremos o risco de cair na mesmice.

Com respeito ao uso de instrumentos de coleta de dados, as pesquisas (ZEICHNER, 2009; ANDRÉ, 2009) também coincidem na deficiente descrição dos mesmos, em que não se justificam adequadamente. $\mathrm{O}$ uso combinado de diferentes instrumentos para verificar determinadas situações é ainda insuficiente. A seguinte afirmação de André é convincente:

Muitos estudos examinados neste relatório não fornecem nenhuma informação sobre como os instrumentos usados para a coleta de dados foram desenvolvidos e validados ou como sua confiabilidade foi avaliada. Essa falta de informação nos relatórios de pesquisa publicados necessariamente enfraquece as alegações que os pesquisadores podem fazer sobre os efeitos do que foi examinado (ANDRÉ, 2009, p. 18).

Neste ponto, temos nos detido nessas três investigações porque elas coincidem em algumas das fragilidades metodológicas mais notórias da disciplina em análise e, porque ao mesmo tempo, essas limitações destacam certos pontos de giro que se devem operar na área, também nesse aspecto. $\mathrm{O}$ que as pesquisas revelam é o uso pontual e descontextualizado de procedimentos de coleta e de análise de dados, dentre eles: depoimentos, questionários, entrevistas, grupos focais, revisão documental e bibliográfica etc. Esses procedimentos, quando adequadamente contextualizados são eficientes, mas, quase sempre, permitem apenas obter resultados bibliográficos, diagnósticos de necessidades, estados da arte, 
descrições de determinadas situações educativas etc., com escasso impacto na formação profissional e na transformação da prática educativa.

Para uma virada metodológica no progresso da área, deveria se pensar em converter a formação de professores numa ciência pluridisciplinar e plurimetodológica, deixando claro que os diferentes tipos de estudo são todos válidos, sempre que se justifiquem corretamente suas necessidades, objetivos e fundamentos teóricos. Na nossa concepção, teoria e método se complementam numa unidade dialética, porém, o método faz parte da teoria que o gera e na qual se insere. Isso significa que a diversificação dos métodos de pesquisa implica a adequada justificação teórica dos mesmos. É preciso, por exemplo, diversificar instrumentos e procedimentos para estudar um mesmo assunto ou problema; combinar equilibradamente análises qualitativas e quantitativas; realizar estudos de caso aprofundados, investigações longitudinais e experimentos pedagógico-didáticos no campo da formação, devidamente fundamentados em referencias de peso. Sem esse tipo de estudos, dificilmente a área pode produzir conhecimento novo e relevante.

Outro aspecto de primeira importância no plano metodológico é o problema da contextualização da pesquisa, dos instrumentos, e da análise de dados. É óbvio que um tratamento mais cuidadoso dos contextos nos relatórios de investigação, uma maior atenção à validade e à confiabilidade dos instrumentos, assim como aos registros de coleta de dados, se relaciona diretamente com a qualidade dos resultados e sua defesa por parte dos investigadores. Mas aqui a questão crucial é o tema da contextualização.

Como se conhece, a perspectiva gnosiológica (positivista) e a fenomenológica da ciência moderna, em certas condições existentes ou criadas artificialmente, fazem abstração da presença mediadora do contexto da praxe na qual está sempre inserida a atividade cognitiva humana. Preocupados com essa limitação epistemológica da ciência clássica, ou epistemologia de primeira ordem (SOTOLONGO; DELGADO, 2006, p. 55) advertem que: "Parece ocioso, mas não é, destacar o preço epistemológico que se paga com semelhante abstração, sobre todo quando se realiza de maneira não consciente". Ressaltamos que a abstração das 
mediações socioeducativas que até hoje afetam a qualidade das pesquisas na formação de professores se deve a duas razões interdependentes: de uma parte, a débil formação filosófica dos pesquisadores; e de outra, a inconsciência de permanecer atrelados ao paradigma investigativo da modernidade e seus piores desvios. É possível afirmar que o paradigma da ciência moderna está hoje numa crise sem reversão. Essa compreensão nos coloca diante de outro ponto de giro que devemos dar na condução metodológica de nossas pesquisas na área de formação de professores.

O novo enfoque metodológico que alegamos para a formação de professores passaria, necessariamente, pelo que Sotolongo e Delgado (2006) chamam da mútua contextualização do objeto e do sujeito através da praxe quotidiana. No modelo clássico de investigação, característico da modernidade, existia a proclividade para privilegiar enfoques objetivantes (gnosiologia), subjetivantes (fenomenologia), próprios da bipolaridade existente na relação objeto/sujeito, quando se toma sem contextualizá-la.

Perante a figura dicotômica clássica que separa a unidade objeto-sujeito da investigação, favorecendo sempre um dos polos da relação (objetivismo versus subjetivismo), precisa-se apreender a essência da relação objeto-sujeito, sem reduzi-la a um dos extremos da dualidade, através de uma instância mediadora que contenha os dois. "Essa instancia mediadora não é outra que a fornecida pela praxe cotidiana humana, que conjuga em si mesma os aspectos objetivos e subjetivos do que fazer quotidiano dos homens e mulheres sociais" (SOTOLONGO; DELGADO, 2006, p. 54). Essa nova perspectiva poderia conduzir a uma mudança na compreensão da verdade científica na área de formação de professores.

\section{Formação dos professionais}

Junto às dificuldades teóricas e metodológicas e as transformações epistemológicas que a área precisa enfrentar, coloca-se também a problemática da formação dos profissionais da educação. Como superar as necessidades e obstáculos que hoje apresenta a área de formação de 
professores sem profissionais (professores e pesquisadores) solidamente formados? O papel dos profissionais da educação tem absoluta centralidade nesta discussão. Sem dúvida, eles são a origem por onde começar. Claro que nos deparamos com uma trama complexa de fatores que interferem no desenvolvimento da educação, mas há um aspecto no qual parece haver consenso entre políticos, investigadores, formadores, gestores, imprensa e jornais científicos: são importantes os problemas de infraestrutura, os curriculares, as políticas públicas, o financiamento da educação, as condições de emprego, carreira e salário, os materiais docentes, mas todo isso é secundário perante a urgência histórica de formar bons pesquisadores e melhores professores. Em respeito à centralidade do professor, Gatti (2009) afirma:

O professor não é descartável, nem substituível, pois, quando bem formado, ele detém um saber que alia conhecimento e conteúdo à didática e às condições de aprendizagem para segmentos diferenciados. Educação para se ser humano se faz em relações humanas profícuas" (GATTI, 2009, p. 92).

Em direção contrária a esses pressupostos, as pesquisas revelam numerosas fragilidades na formação dos licenciados em educação. Em virtude da síntese, nos remitimos apenas a duas delas (GATTI, 2009; ROMANOWSKI, 2014). Na primeira dessas pesquisas se resumem oito pontos negativos que interferem na formação dos licenciados:

a) ausência de uma perspectiva de contexto social e cultural e do sentido social dos conhecimentos; b) a ausência nos cursos de licenciatura, e entre seus docentes formadores, de um perfil profissional claro de professor enquanto profissional [...]; c) a falta de integração das áreas de conteúdo e das disciplinas pedagógicas dentro de cada área e entre si; d) a escolha de conteúdos curriculares; e) a formação dos formadores; f) a falta de uma carreira suficientemente atrativa e de condições de trabalho; g) ausência de módulo escolar com certa durabilidade em termos de professores 
e funcionários; h) precariedade quanto a insumos para o trabalho docente" (GATTI, 2009, p. 97-98).

Em pesquisa realizada por Romanowski (2014) se realiza uma análise dos resultados das investigações referentes a mudança realizada nos cursos de licenciatura após LDB de 1996. Algumas das conclusões da autora são as seguintes:

As pesquisas realizadas nos anos de 1990 corroboram as críticas e denúncias realizadas desde a década de 1980 sobre os cursos de licenciatura, que indicam a permanência da estrutura universitária departamentalizada, cursos aligeirados e realizados em condições precárias impedindo a superação das questões existentes nos processos de formação docente [...] Os esforços para que os cursos de licenciatura tenham identidade própria, formação consistente articulada com as finalidades da escola e com a sociedade como a inclusão, a diversidade, tem logrado pouco êxito. O que se vê é a manutenção de uma formação centrada no domínio acadêmico dos conhecimentos dos conteúdos das disciplinas, direcionando a formação para o bacharelado (ROMANOWSKI, 2014, p. 12).

Nessa mesma direção, Libâneo (2011) realizou uma pesquisa sobre o ensino de Didática e das Metodologias de ensino nos cursos de Pedagogia no estado de Goiás. Entre as conclusões mais importantes a que chegou o autor encontra-se a seguinte:

As ementas das disciplinas agrupadas na categoria "conhecimentos referentes a formação profissional específica" [...] mostram-se bastante genéricas e teoricamente frágeis, mantendo ainda forte apoio no caráter instrumental. Está ausente a preocupação epistemológica, que se reflete na não articulação entre conteúdos e metodologias específicas das diferentes matérias. Ao mesmo tempo, parece haver um distanciamento do objeto da didática e das metodologias específicas da mediação da aprendizagem dos alunos. Nesse contexto, é preocupante a quase ausência [...] de disciplinas de conteúdos específicos do ensino fundamental (LIBÂNEO, 2011, p. 43-44). 
As conclusões a que também chegam Gatti, Barreto e André (2011) sobre a formação dos pedagogos em nível nacional coincidem, quase integramente, com as conclusões de Libâneo:

Verificou-se que o currículo proposto por esses cursos tem uma característica fragmentária, apresentando um conjunto disciplinar bastante disperso. [...] nas disciplinas de formação profissional, predominam os referenciais teóricos de natureza sociológica, psicológica ou outros, com associação em poucos casos às práticas educacionais. $\mathrm{O}$ estudo das ementas das disciplinas revela, antes de tudo, maior preocupação com o oferecimento de teorias políticas, sociológicas e psicológicas para a contextualização dos desafios do trabalho nas redes de ensino. Isso é realmente muito importante para o trabalho consciente do (a) professor (a), mas não suficiente para o desempenho de suas atividades de ensino. Pouquíssimos cursos propõem disciplinas que permitam algum aprofundamento em relação à educação infantil, e, mesmo assim, o aspecto metodológico do trabalho com crianças é pouco referido. Quanto aos estágios supervisionados, que, em princípio, deveriam constituir-se em espaços privilegiados para a aprendizagem da relação das teorias com as práticas possíveis, não se obteve evidências, na grande maioria dos casos, sobre como são concebidos, planejados e acompanhados (GATTI, BARRETO, ANDRÉ, 2011, p. 114).

As pesquisas de André (2009, 2010), mencionadas anteriormente, têm revelado também a fragilidade existente na formação dos pesquisadores da área em estudo. Destacamos apenas mais um aspecto relevante sobre a necessidade de formar melhores pesquisadores para o campo disciplinar da formação de professores. Sobre isso Zeichner (2009) afirma:

É opinião do nosso painel que se vier a acontecer uma significativa melhora no campo da pesquisa sobre formação docente, maiores investimentos devem ser feitos na formação de pesquisadores, no financiamento de estudos que desenvolverão nosso conhecimento sobre a formação de professores e no fortalecimento do processo por meio do qual os resultados de pesquisa são checados. Concentrar uma parte dos programas de formação de pesquisadores [...] na pesquisa sobre 
formação de professores é uma maneira de prover suporte adicional para os pesquisadores da formação docente (ZEICHNER, 2009, p. 31).

Resumindo, num inventário dos aspectos negativos reiterados nas conclusões das pesquisas citadas sobre a formação de professores e pesquisadores, destacam-se as seguintes debilidades: fragmentação curricular, dispersão e enfoque disciplinar, conteúdos pouco relevantes para o exercício da profissão, fragilidade teórica e metodológica, desconexão entre conteúdos e metodologias de ensino, desconexão entre metodologias e epistemologia das disciplinas escolares e um longo etc.

A nossa conclusão sobre este aspecto é a seguinte: uma mudança radical na formação dos professores e pesquisadores educacionais deveria passar, a nosso juízo, por no mínimo seis transformações principais: a) o estabelecimento de Programas eficientes de formação profissional, devidamente financiados pelo Estado, com a participação direta de políticos, investigadores, gestores e formadores de formadores; b) melhoria dos processos de seleção e recrutamento dos estudantes de magistério e dos futuros pesquisadores da área; c) a formação dos professores formadores e dos gestores dos cursos de formação a altura da responsabilidade social, científica e política que o caso requer; d) reforma curricular profunda de caráter pluridisciplinar e interdisciplinar, capaz de colocar a formação e a pesquisa no plano da epistemologia de segunda ordem, na qual a relação objeto-sujeito seja considerada uma unidade dialética mediada pela praxe socioeducativa situada, na qual se produz a formação dos profissionais e se realiza pesquisa; e) políticas que garantam Programas de formação continuada de professores e pesquisadores, devidamente financiados pelo Estado, e elaborados com a participação direta de políticos, investigadores, gestores e formadores de formadores; f) políticas que assegurem a permanência na profissão de professores e pesquisadores, com respaldo salarial, condições de emprego e planos de carreira condicentes com o valor social desses profissionais.

A formação de professores e pesquisadores concebida na sua real complexidade, que tenha em conta os diferentes níveis de realidade que 
perpassam a formação, assim como as múltiplas conexões existentes entre as disciplinas que integram a área, deve proporcionar aos formandos experiências cuidadosamente pensadas em projetos de pesquisa, seminários interdisciplinares e solução de problemas pedagógicos diversos, de maneira que se ensine aos futuros profissionais a pensar criteriosamente a educação e a ampliar seus conhecimentos e capacidades muito além de suas áreas de especialização.

\section{Referências}

ANDRÉ, M. et al. Estado da Arte da Formação de Professores no Brasil. Educação \& Sociedade, Ano XX, n. 68, p. 301-309, 1999. Disponível em: <http://www.scielo.br/pdf/es/v20n68/a15v2068.pdf >. Acesso em: 1 dez. 2015.

ANDRÉ, M. A produção acadêmica sobre formação de professores: um estudo comparativo das dissertações e teses defendidas nos anos 1990 e 2000. Formação Docente. Revista Brasileira de Pesquisa sobre Formação de Professores. v. 1, n. 1, p. 1-12, 2009. Disponível em: <http://formacaodocente.autenticaeditora.com. br/artigo/exibir/1/7/1>. Acesso em $1 \mathrm{dez} .2015$.

ANDRÉ, M. Formação de professores no Brasil (1990-1998). Brasília: MEC/Inep/ Comped, 2002. (Série estado do conhecimento, 6).

ANDRÉ, M. Formação de professores: a constituição de um campo de estudos. Educação \& Sociedade, v. 33, n. 3, p. 174-181, 2010. Disponível em: <http://revistaseletronicas.pucrs.br/ojs/index.php/faced/article/view/8075/5719〉. Acesso em: 1 dez. 2015.

AQUINO, O. F.; BORGES, M. C. Políticas públicas, formação de professores e didática: resultados de uma triangulação. Inter-ação (UFG. Online), v. 39, p. 199214, 2014. Disponível em: <http://www.revistas.ufg.br/index.php/interacao/ article/view/18756/16362>. Acesso em: 10 out. 2014.

BOLÍVAR, A. La identidad profesional del profesorado de secundaria: crisis y reconstrucción. Málaga, España: Ediciones Algibe, 2006. 
BRZEZINSKI, I. Formação de profissionais da educação (1997-2002). Brasília: Ministério da Educação, Instituto Nacional de Estudos e Pesquisas Educacionais Anísio Teixeira, 2006. (Série estado do conhecimento, 10).

DALBEN, Â. I. L. F. Convergências e tensões no campo da formação e do trabalho docente. Belo Horizonte: Autêntica, 2010.

GATTI, B. A. Formação de professores: condições e problemas atuais. Revista brasileira de formação de professores - RBFP, v. 1, n. 1, 2009. Disponível em: <http:// s5a2fd2a49624f65c.jimcontent.com/download/version/1363701082/module/6300835483/name/Forma\%C3\%A7\%C3\%A3o\%20de\%20professores\%20 (condi\%C3\%A7\%C3\%B5es\%20e\%20problemas\%20atuais >. Acesso em: 1 jan. 2015.

GATTI, B. A.; BARRETO, E.; ANDRÉ, M. Políticas docentes no Brasil: um estado da arte. Brasília: UNESCO, 2011.

GATTI, B. A. Implicações e perspectivas da pesquisa educacional no Brasil contemporâneo. Cadernos de Pesquisa, n. 113, p. 65-81, jul. 2001. Disponível em: <http://www.uneb.br/gestec/files/2011/10/Implica\%C3\%A7\%C3\%B5es-eperspectivas-da-pesquisa-educacional-no-Brasil-contempor\%C3\%A2neoa04n1131.pdf >. Acesso em: 1 jan. 2015.

GOUVEIA, A. J. A pesquisa educacional no Brasil. Cadernos de Pesquisa, n. 1, p. 1-48, jul. 1971. Disponível em: <http://www.uneb.br/gestec/files/2011/10/ Implica\%C3\%A7\%C3\%B5es-e-perspectivas-da-pesquisa-educacional-no-Brasilcontempor\%C3\%A2neo-a04n1131.pdf >. Acesso em: 1 jan. 2015.

GOUVEIA, A. J. A pesquisa sobre educação no Brasil: desde 1970 para cá. Cadernos de Pesquisa, n. 19, p. 75-79, dez. 1976. Disponível em: <http://www. fcc.org.br/pesquisa/publicacoes/cp/arquivos/360.pdf >. Acesso em: 1 jan. 2015.

GOUVEIA, A. J. Algumas reflexões sobre a pesquisa educacional no Brasil. Revista Brasileira de Estudos Pedagógicos, v. 86, n. 213-214, p. 143-146, dez. 2005. Disponível em: <http://rbep.inep.gov.br/index.php/RBEP/article/viewFile/67/69>. Acesso em: 1 jan. 2015. 
LIBÂNEO, J. C. Panorama do ensino da Didática, das metodologias específicas e das disciplinas conexas nos cursos de Pedagogia: repercussões na qualidade da formação profissional. In: Andréa Maturano Longarezi; Roberto Valdés Puentes (orgs.) Panorama da Didática: ensino, prática e pesquisa. Campinas, SP: Papirus, 2011. p. 11-50. (Coleção Magistério: Formação e Trabalho Pedagógico).

MARCELO GARCIA, C. Formação de professores. Para uma mudança educativa. Porto: Porto Editora, 1999.

MARCELO GARCIA, C. Pesquisa sobre a formação de professores. O conhecimento sobre aprender a ensinar. Revista Brasileira de Educação, n. 9. p. 51-75, 1997. Disponível em: <https://www.researchgate.net/publication/242399143_ Pesquisa_sobre_a_formao_de_professores_O_conhecimento_sobre_aprender_a_ ensinar >. Acesso em: 3 jan. 2015.

MELLO, G. N. A pesquisa educacional no Brasil. Cadernos de Pesquisa, n. 46, p. 67-72, ago. 1983. Disponível em: <http://www.fcc.org.br/pesquisa/publicacoes/cp/arquivos/579.pdf >. Acesso em: 3 jan.2015.

NICOLESCU, B. La transdisciplinariedad. Manifiesto. Trad. Norma Núñez-Dentin; Gérard Dentin. [s.l.]: Ediciones Du Rocher, 2006.

OlIVEIRA, Maria Rita. 20 Anos de ENDIPE. In: CANDAU, V. (Org.). Didática, currículo e saberes escolares. Rio de Janeiro: DP\&A, 2000. p. 161-176.

QUEIROZ, V. R. F. A formação de professores nas pesquisas nacionais e estrangeiras: tendências e desafios. Inter-Ação, v. 38, n. 1, 2013. Disponível em: <http:// www.revistas.ufg.br/index.php/interacao/article/view/18777〉. Acesso em: 5 jan. 2015.

RAMALHO, B. L; NÚÑEZ, I. B.; PRADA, L. E. A. A pesquisa sobre a formação de professores nos programas de pós-graduação em educação: o caso do ano 2000. p. 1-15, 2000. Disponível em: <http://www.comperve.ufrn.br/conteudo/observatorio/ uploads/publicacoes/artigos_05022013075924.pdf >. Acesso em: 2 fev. 2012. 
ROMANOWSKI, J. P. Apontamentos em pesquisas sobre formação de professores: contribuições para o debate. Revista Diálogo Educacional, v. 12, n. 37, p. 905-924, 2012. Disponível em: <http://www2.pucpr.br/reol/index.php/ dialogo?dd99=pdf\&dd1=7210 >. Acesso em: 2 fev. 2012.

ROMANOWSKI, J. P.; MARTINS, P. L. O. Reformulação dos cursos de licenciatura no Brasil. In: XVII ENDIPE- Encontro Nacional de Didática e Prática de Ensino. Fortaleza, CE, 2014. p. 1-15.

SOARES, Magda. 20 Anos de ENDIPE. In: CANDAU, Vera. (Org.). Didática, currículo e saberes escolares. Rio de Janeiro: DP\&A, 2000. p. 177-192.

SOTOLONGO CODINA, P. L.; DELGADO DÍAZ, Carlos Jesús. La revolución contemporánea del saber y la complejidad social: hacia unas ciencias sociales de nuevo tipo. 1a. ed. Buenos Aires: Consejo Latinoamericano de Ciencias Sociales - CLACSO, 2006. ZEICHNER, Kenneth M. Uma agenda de pesquisa para a formação docente. Revista brasileira de pesquisa sobre formação docente, v. 1, n. 1. p. 13-40, 2009. Disponível em: 〈http://formacaodocente.autenticaeditora.com.br/artigo/exibir/1/8/1 >. Acesso em: 2 fev. 2012.

Recebido: 30/07/2016

Received: 07/30/2016

Aprovado: 20/10/2016 Approved: 10/20/2016 